\title{
Ewing Sarcoma/Peripheral Neuroectodermal Tumor of Bone and Soft Tissue in Infants: A Report from Children Cancer Hospital of Egypt
}

\author{
Enas El Nadi ${ }^{1,2, *}$, Ahmed El Ghoneimy ${ }^{3}$, Maged El Shafiey ${ }^{4,5}$, Hala Taha ${ }^{6,7}$, \\ Mohamed Saad Zaghlool $^{8,9}$, Iman Zaki ${ }^{10,11}$, Nehal Kamal ${ }^{12}$, Nada Mounir ${ }^{12}$, Manal Amin ${ }^{2,13}$ \\ ${ }^{1}$ Department of Clinical Oncology, Faculty of Medicine, Beni-Suef University, Beni-Suef, Egypt \\ ${ }^{2}$ Pediatric Oncology Department, Children Cancer Hospital of Egypt, Cairo, Egypt \\ ${ }^{3}$ Orthopedics, Children Cancer Hospital of Egypt, Cairo, Egypt \\ ${ }^{4}$ Surgical Oncology, Children Cancer Hospital of Egypt, Cairo, Egypt \\ ${ }^{5}$ Surgical Oncology National Cancer Institute, Cairo, Egypt \\ ${ }^{6}$ Surgical Pathology, Children Cancer Hospital of Egypt, Cairo, Egypt \\ ${ }^{7}$ Surgical Pathology National Cancer Institute, Cairo, Egypt \\ ${ }^{8}$ Radiotherapy Department, Children Cancer Hospital of Egypt, Cairo, Egypt \\ ${ }^{9}$ Radiotherapy Department, National Cancer Institute, Cairo, Egypt \\ ${ }^{10}$ Radiology Department, Children Cancer Hospital of Egypt, Cairo, Egypt \\ ${ }^{11}$ Radiology Department, National Cancer Institute, Cairo, Egypt \\ ${ }^{12}$ Clinical Research Department, Children Cancer Hospital of Egypt, Cairo, Egypt \\ ${ }^{13}$ Pediatric Oncology Department, National Cancer Institute, Cairo, Egypt \\ Email address: \\ inas.mohsen@57357.com (E. El Nadi) \\ ${ }^{*}$ Corresponding author
}

\section{To cite this article:}

Enas EL Nadi, Ahmed EL Ghoneimy, Maged EL Shafiey, Hala Taha, Mohamed Saad Zaghlool, Iman Zaki, Nehal Kamal, Nada Mounir, Manal Amin. Ewing Sarcoma/Peripheral Neuroectodermal Tumor of Bone and Soft Tissue in Infants: A Report from Children Cancer Hospital of Egypt. Cancer Research Journal. Vol. 9, No. 1, 2021, pp. 14-22. doi: 10.11648/j.crj.20210901.13

Received: December 22, 2020; Accepted: January 11, 2021; Published: January 25, 2021

\begin{abstract}
Introduction: Ewing sarcoma is an aggressive malignancy of bone and soft tissue. It is rare in children under age 5 years. Ewing's sarcoma family tumors include classic Ewing's sarcoma, primitive neuroectodermal tumour and Askin tumor. ES is the second most common variety of primary bone cancer in adolescents and young adults. The treatment strategy for ES is characterized by multi-disciplinary collaboration between pediatric oncologists, radiation oncologists, and orthopedic surgeons. Although the survival rate of ES patients has improved, their prognosis remains unsatisfactory. The treatment of ES is still challenging specially in age group below 3 years. Patients and methods: A Retrospective study of children below 3 years with a diagnosis Ewing Sarcoma/PNET presented to CCHE from July 2009 till December 2018. Results: A review of 46 patients with age ranged from 3 months to 3 years with Mean of age was 1.8. Primary site was Osseous and extraosseus in 23 infant patients for each. Main site was mainly axial in 28 cases $(60.8 \%)$. Cases were treated according to COG protocol. Infantile Ewing sarcoma OS and EFS at 5-years OS were 75.5\% and 66.7\%. Conclusion: Patients below 3 years represent an unusual young age group. Conclusion: ES/PNET in age below 3 years is a unique age group with a different management and outcome.
\end{abstract}

Keywords: Ewing Sarcoma, Survival, Infants 


\section{Introduction}

Ewing sarcoma is malignant tumor of bone and soft tissue and it accounts for $3 \%$ of all pediatric malignancies [1]. It represents the second most common primary malignant bone cancer in children and adolescents [2]. The term Ewing sarcoma family of tumors ESFT include older terms such as: peripheral primitive neuroectodermal tumor, Askin tumor, (Ewing sarcoma of chest wall), and extraosseous Ewing sarcoma.

ESFT are small round cells of neuroectodermal origin and very rarely affect newborns [5]. Diagnosis of EWS/PNET depends mainly on immunohistochemistry and molecular/genetic assays. ESFT are highly aggressive and patient prognosis is typically very poor so treatment remains a challenge [5].

ESFT has a characteristic chimeric transcript, resulting from the fusion of the EWS gene with genes that encode for structurally related transcription factors, usually FLI1 or ERG2 [6]. Knowledge of the biology of Ewing sarcoma has been growing but has yet to significantly impact or produce new treatments [9].

ES can occur in individuals of any age group, but is most commonly seen in adolescent patients, with a peak incidence between 10 and 15 years of age. Thirty percent of cases have been observed in children under the age of 10 , but the condition is rare in children under age 5 and in adults over age 30 [3]. Ewing sarcoma of infants is rare constituting 2.6\% of all patients registered in the Intergroup Ewing's Sarcoma Study (IESS) [8].

One recent study on ES patients before 6 years showed that axial tumors were more common in this subgroup and that outcomes were similar to that of older patients [4].

ES affects the skeletal system and accounts for $4-10 \%$ of all types of bone cancers in long bones. Lower extremities, pelvis, upper extremities, axial skeleton, ribs, and head and neck region are the most common locations affected in descending order [12]. It is more prevalent in males and the bones of the pelvis and the lower extremities are the most common sites of disease [18].

The treatment strategy for ES should have multidisciplinary collaboration between pediatric oncologists, radiation oncologists, and orthopedic surgeons [7].
Incorporating advances in diagnosis, surgery, chemotherapy, and radiation has substantially improved the survival rate of people with localised Ewing's sarcoma to 70\% [20].

Using intensive systemic chemotherapy with multiple anticancer drugs is the standard treatment modality for ES. Neoadjuvant chemotherapy eliminates any micro-metastases, decreases tumor load, and helps in selecting postoperative anticancerous drugs [14].

Effective local control measures is important with wide negative margins; definitive radiation or surgical therapy to eradicate all known disease; and consolidation with adjuvant chemotherapy to reduce the likelihood of tumour recurrence [20].

ES outcome improved recently but late complications and secondary malignancies remain the major risks specially in young age group. It is necessary to do long-term follow-up to detect secondary malignancies, any recurrences or relapses, muscular or skeletal problems, and any other complications [14].

\section{Patients and Methods}

A retrospective cohort study utilizing data collected at children cancer hospital of Egypt from 2009 to 2018. Patients had a diagnosis Ewing sarcoma, peripheral primitive neuroectodermal tumor (PNET), or Askin tumor between 0 and 3 years of age were included.

Patient demographics and clinical characteristics were collected; age, sex, tumor volume, site, stage, management of the disease. Survival was studied by overall and disease free survival. Survival was correlated to different factors.

All patients had initial lab and clinical assessment, radiological assessment $\mathrm{CT} / \mathrm{MRI}$ to local sites and metastatic work up including: CT Chest, Bone Scan, bilateral bone marrow aspirate and biopsy to verify the diagnosis pathologically.

Data regarding treatment, consisting of surgery and radiation therapy and chemotherapy were also collected.

Patients were treated with neoadjuvant chemotherapy protocol Adapted from COG (AEWS0031). Patients had local control at week 12 after 5 cycles of neoadjuvant chemotherapy.

\begin{tabular}{|c|c|c|c|c|c|c|c|c|c|c|c|c|c|c|}
\hline Week & 0 & 2 & 4 & 6 & 8 & 10 & 14 & 16 & 18 & 20 & 22 & 24 & 26 & 28 \\
\hline & $\begin{array}{c}\mathrm{V} \\
\mathrm{D}^{*} \\
\mathrm{C}\end{array}$ & $\begin{array}{l}\mathrm{I} \\
\mathrm{E}\end{array}$ & $\begin{array}{c}\mathrm{V} \\
\mathrm{D}^{*} \\
\mathrm{C}\end{array}$ & $\begin{array}{l}\mathrm{I} \\
\mathrm{E}\end{array}$ & $\begin{array}{c}\mathrm{V} \\
\mathrm{D}^{*} \\
\mathrm{C}\end{array}$ & $\begin{array}{l}\mathrm{I} \\
\mathrm{E}\end{array}$ & $\begin{array}{c}\mathrm{V} \\
\mathrm{D}^{*} \\
\mathrm{C}\end{array}$ & $\begin{array}{l}\mathrm{I} \\
\mathrm{E}\end{array}$ & $\begin{array}{c}\mathrm{V}^{*} \\
\mathrm{D}^{*} \\
\mathrm{C}\end{array}$ & $\begin{array}{l}\mathrm{I} \\
\mathrm{E}\end{array}$ & $\begin{array}{l}\mathrm{V} \\
\mathrm{C}\end{array}$ & $\begin{array}{l}\mathrm{I} \\
\mathrm{E}\end{array}$ & $\begin{array}{l}\mathrm{V} \\
\mathrm{C}\end{array}$ & $\begin{array}{l}\mathrm{I} \\
\mathrm{E}\end{array}$ \\
\hline & & & & & & \multicolumn{2}{|c|}{ Local Control } & & & & & & & Delayed Surgery \\
\hline \multicolumn{8}{|c|}{$\begin{array}{l}\text { Vincristine } 2 \mathrm{mg} / \mathrm{m}^{2} \mathrm{IV} \text { push (Max. } 2 \mathrm{mg} / \text { dose) } \\
\text { Doxurubicin } 37.5 \mathrm{mg} / \mathrm{m}^{2} \text { over } 4 \mathrm{hr} \times 2 \text { days (cumulative dose } 375 \mathrm{mg} / \mathrm{m}^{2} \text { ) } \\
\text { Cyclophosphamide } 1.2 \mathrm{gm} / \mathrm{m}^{2} \text { over } 1 \mathrm{hr} \text {. } \\
\text { sna } 360 \mathrm{mg} / \mathrm{m}^{2} / \text { dose } 30 \mathrm{~min} \text { before Cyclophosphamide and at } 3,6,9 \mathrm{hr} \\
\text { tration } \mathrm{G} 5 \% \mathrm{Ns} 125 \mathrm{ml} / \mathrm{m}^{2} / \mathrm{hr} \text { over } 8-12 \mathrm{hr} \text { post Cyclophosphamide }\end{array}$} & \multicolumn{7}{|c|}{$\begin{array}{l}\mathbf{E}=\text { Etoposide } 100 \mathrm{mg} / \mathrm{m}^{2} / \text { day over } 2 \mathrm{hr} \times 5 \text { days } \\
\text { I = Ifosfamide } 1.8 \mathrm{gm} / \mathrm{m}^{2} \text { over } 22 \mathrm{hrs} \times 5 \text { days } \\
\text { Mesna }(360 \mathrm{mg} / \mathrm{m} 2) 30 \mathrm{~min} \text { before Ifosfamide and at } 3,6,9,12 \mathrm{hrs} \\
\text { Hydration } \mathrm{G} 5 \% \text {.Ns } 125 \mathrm{ml} / \mathrm{m}^{2} / \mathrm{hr} \text { over } 24 \mathrm{hr}\end{array}$} \\
\hline
\end{tabular}

Figure 1. Neoadjuvant chemotherapy protocol Adapted from COG (AEWS0031). 


\section{Pathology}

\subsection{Microscopic Picture}

ES has sheets of uniform small round tumor cells with round nuclei and little cytoplasm with no matrix formation. ES tumor cells have uniform findings with few mitoses. ES also demonstrates morphological features showing neural differentiation, as rosette formation.

\subsection{Immunohistochemistry}

In over $90 \%$ of ES cases, positivity for CD99, a product of the MIC2 gene, is detected on the cytoplasmic membrane.

Positivity for neural markers such as S-100 protein and PGP9.5 is sometimes detected, and vimentin positivity is also commonly observed. Atypical ES, a variant of ES composed of large cells, has also been reported. In addition, ES composed of spindle-shaped and adamantinoma-like cells, as well as other variants have also been reported.

\subsection{Molecular Diagnosis}

The EWS-FLI1 fusion gene, which is caused by the $\mathrm{t}(11$; 22) (q24; q12) translocation, is the most common type of fusion gene ( $85 \%$ of ES tumors).

\section{Results}

Table 1. Patients demographics and clinical characteristics.

\begin{tabular}{|c|c|c|}
\hline \multicolumn{3}{|l|}{ Age } \\
\hline$<1$ year $(<3$ months $)$ & 7 & $15.2 \%$ \\
\hline $1-3$ years & 39 & $84.8 \%$ \\
\hline \multicolumn{3}{|l|}{ Sex } \\
\hline Male & 39 & $84.8 \%$ \\
\hline Female & 7 & $15.2 \%$ \\
\hline \multicolumn{3}{|l|}{ Localized } \\
\hline \multicolumn{3}{|l|}{ Metastatic } \\
\hline Chest metastasis (5) & 39 & $84.8 \%$ \\
\hline Chest and bone mets (1) Soft tissue (1) & 7 & $15.2 \%$ \\
\hline Osseus & 23 & $50 \%$ \\
\hline Soft tissue & 23 & $50 \%$ \\
\hline \multicolumn{3}{|l|}{ Site } \\
\hline Axial & 28 & $60.8 \%$ \\
\hline Peripheral & 18 & $39.1 \%$ \\
\hline Lower limb & 12 & $26.1 \%$ \\
\hline Upper limb & 6 & $13 \%$ \\
\hline Head and neck & 9 & $19.6 \%$ \\
\hline Chest and chest wall & 12 & $26.1 \%$ \\
\hline Pelvis & 4 & \\
\hline Vertebral spine & 3 & \\
\hline \multicolumn{3}{|l|}{ Local control } \\
\hline Surgery & 18 & \\
\hline Radiotherapy & 16 & \\
\hline Both & 9 & \\
\hline \multicolumn{3}{|l|}{ Pathological response } \\
\hline Good responder & 11 & \\
\hline Poor responder & 8 & \\
\hline \multicolumn{3}{|l|}{ Outcome } \\
\hline Alive & 25 & \\
\hline Deathes & 7 & \\
\hline Lost follow up & 1 & \\
\hline
\end{tabular}

A review to patients with a diagnosis of Ewing's Sarcoma below 3 years enrolled from 2009 till December 2018. Forty six patients were studied. They presented $8.3 \%$ of the whole Ewing's Sarcoma patients in CCHE: $\{n=554\}$ ) in the study period.

Patient demographics and clinical characteristics (shown in table 1) as sex, primary tumor site (head, neck, upper limb, lower limb, pelvis, chest/thorax, abdomen, vertebral column/spinal cord) Figure 1 showing the sites of ES patients below 3 years.

Primary tumor localization (axial vs. appendicular; tissue origin (skeletal vs. soft tissue); histology classical Ewing sarcoma vs. PNET (coded as either PNET or Askin tumor). Tumor volume and stage (metastatic vs. localized) were also collected, when available.

Age of patients ranged from 3 months to 3 years, 7 patients $(15.6 \%)$ were below 1 year. The mean of age was 1.8 and median was 1.91 . A male predominance $((n=27) 58.7 \%$ were found.

Tumor Volume were collected in 35 patients, \{11 don't have 3 dimensions for volume tumor . Sixteen patients had a tumor volume $<100 \mathrm{~cm}^{3}$ (34.8\% of patients) and $19 \mathrm{had} \geq$ $100 \mathrm{~cm}^{3}(41.3 \%)$.

Twenty one had tumor volume $<200 \mathrm{~cm}^{3}(45.7 \%)$ and 14 patients had, $\geq 200 \mathrm{~cm}^{3}(30.4 \%)$.

Primary site was mainly osseous in patients above 3 years osseous $(n=383) 75.6 \%$ and extra-osseous (Soft tissue) $(n=$ 125 ) but in patients below 3 years were equally distributed in osseous ES and extraosseus ES with 23 patients for each.

Osseous $(n=23)$

Cranium5 cases (2 Mandible, 2 Orbit, 1 Temporal bone)

Trunk 8 cases $(5$ Chest wall/Ribs, 1 Vertebra, 1 Paravertebral, 1 Scapula)

Upper extremities 2 cases (1 Metacarpal, 1 Radius)

Lower Extremities 8 cases (Femur)

Extra-osseous $(\mathrm{n}=23)$

Head \& Neck

4 cases (1 Posterior aspect of Neck, 1 Orbit, 1 Left External Auditory Canal, 1 LNs: Cervical \& Supraclavicular)

Trunk

13 cases ( 2 Mediastinum, 4 Chest wall/Ribs, 1 Abdomen, 3 Pelvic, 1 Inguinal, 1 Paravertebral, 1 Shoulder)

Upper extremities 2 (1 Wrist, 1 forearm)

Lower Extremities 4 ( 1 thigh, 2 Ankle, 1 Metatarsal)

EWSR1 $\mathrm{t}(11 ; 22)$ (q24; q12) translocation was done in 20 cases out of the 46 cases found to be positive in 9 cases, negative in 3 cases and failed in 8 cases. Main site was the extremity 18 cases (12 cases of lower limb and 6 cases in upper limb) followed by chest wall (12 cases), pelvis 4 cases and 9 Cases head and neck. Vertebral spine 3 cases

In the adult cases 508 cases above 3 years Lower Limbs were the most common $\rightarrow 156$ cases $(30.7 \%)$ but still axial sites is more than peripheral 342 cases out of the 508 cases (distributed in chest, chest wall, head and neck and vertebral column). 
Most of the cases (39 cases) were localized to primary site with 7 cases metastatic.

Eighteen cases (39.1\%) had surgery at local control, sixteen cases had Radiotherapy (34.8\%) and nine cases $(19.8 \%)$ had both.

The outcome of the whole group was studied after exclusion to 13 patient (only 27 patients were studied).

\begin{tabular}{|l|l|}
\hline Upfront surgery & 8 \\
\hline Secondary Malignancy over ALL & 1 \\
\hline Died before Starting Chemotherapy (due to disease Progression) & 1 \\
\hline Died post week 1 & 2 \\
\hline Died before Local Control & 1
\end{tabular}

Figure 2. Status of the whole studied patients.

The 3 Years Overall Survival (figure 2) of 33 patients was $75.5 \%$ and 5 Years Overall Survival was $75.5 \%$.

Twenty five cases were alive, 7 cases were dead and one case Lost FU.
The $3 \& 5$ Years Event-Free Survival (figure 3) $=68.2 \%$ Events $(\mathrm{n}=9)$.

The 3 years overall Survival of the age group below 3 years was compared to patients above 3 years it was slightly better $76.7 \%$ in comparison to $72.7 \%$ but difference was insignificant $(\mathrm{P}$-value $=0.151)$. comparing the EFS of age group below 3 years to older age group $(68.2 \%$ in comparison to $59.7 \%$ difference was still insignificant Pvalue $=0.112$ )

Patient were treated according to COG study chemotherapy protocol was shown in table 1 .

Seven patients relapsed one patient had Local recurrence and another one with both systemic and local. Five patients had systemic relapse ( 3 cases in lung, one case in bone, and another case in brain).

One case died from toxicity and another one died out of secondary malignancy $(n=1)$.

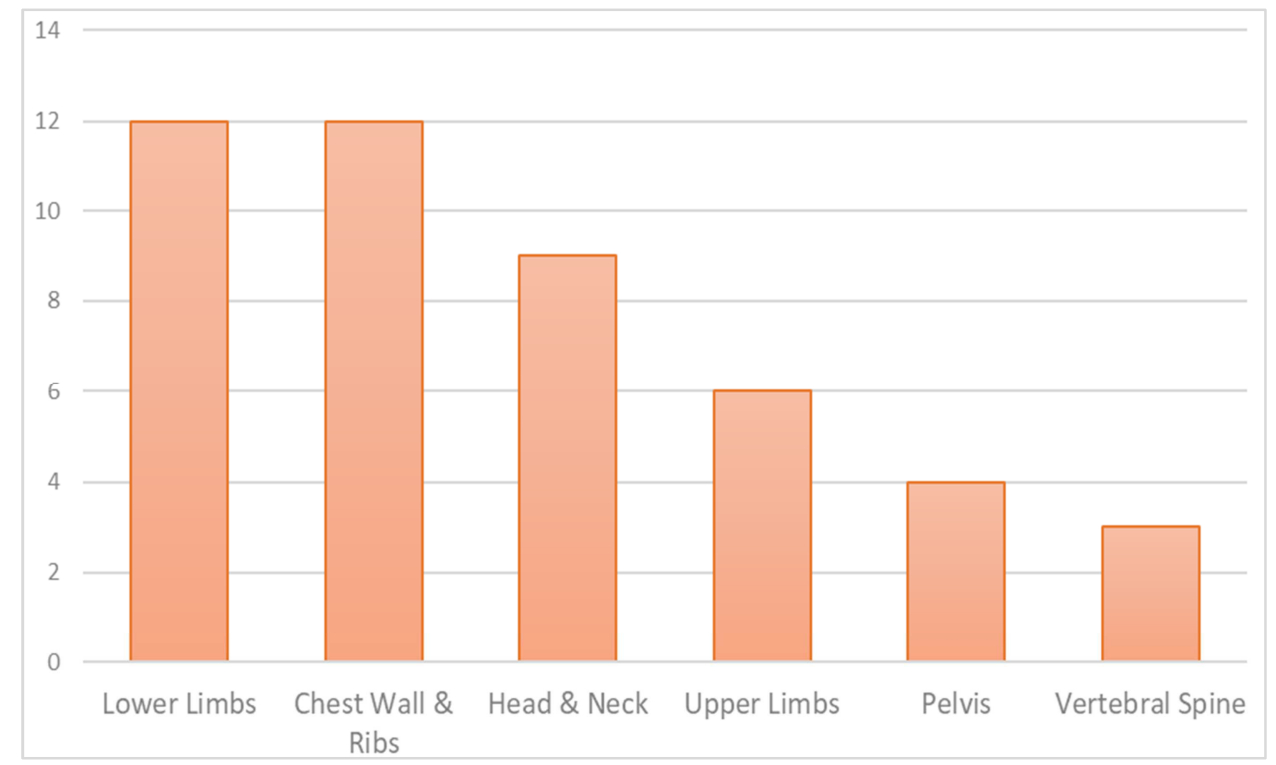

Figure 3. Sites of ES patients below 3 years of age.

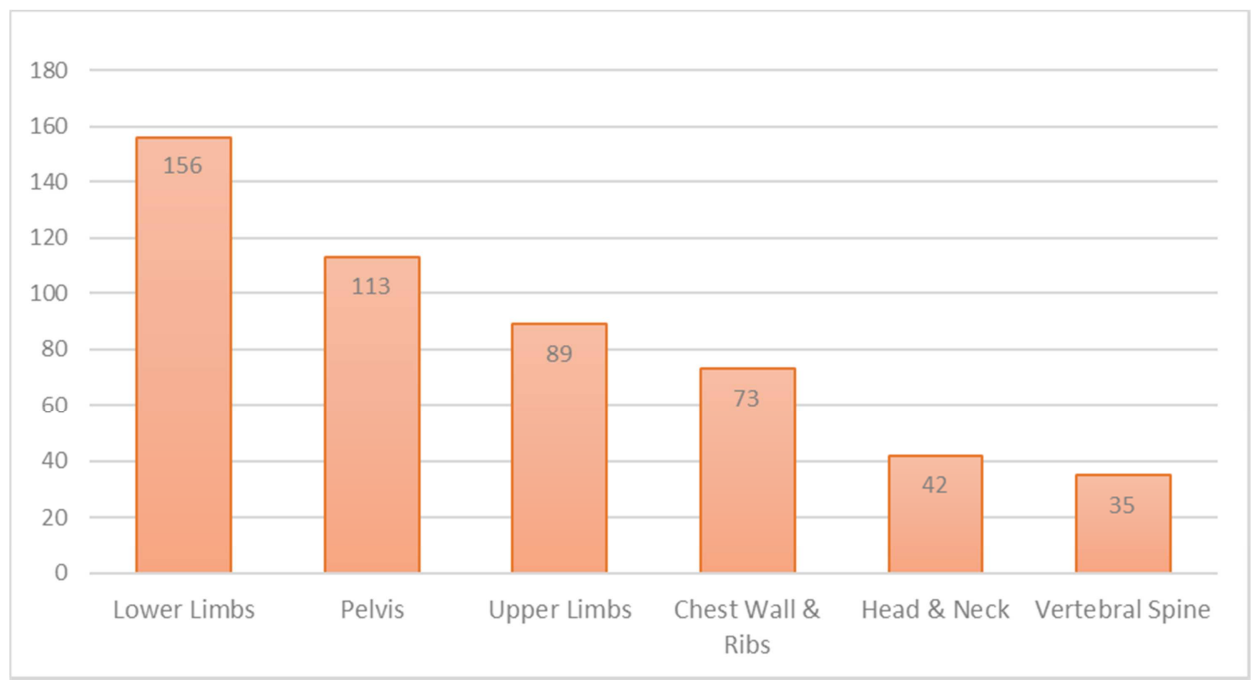

Figure 4. Sites of ES patients above 3 years of age. 


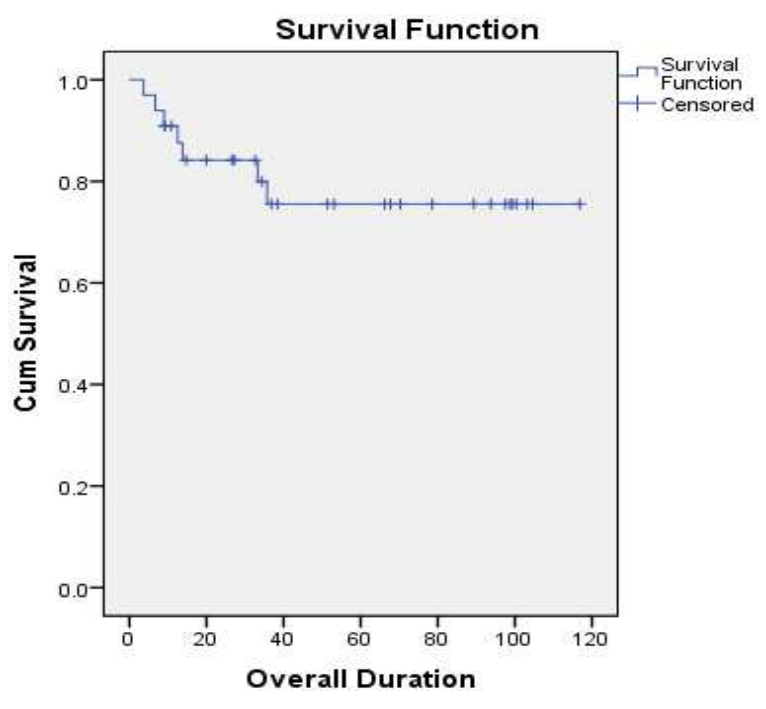

Figure 5. The 3 Years Overall Survival of 33 patients was $75.5 \%$

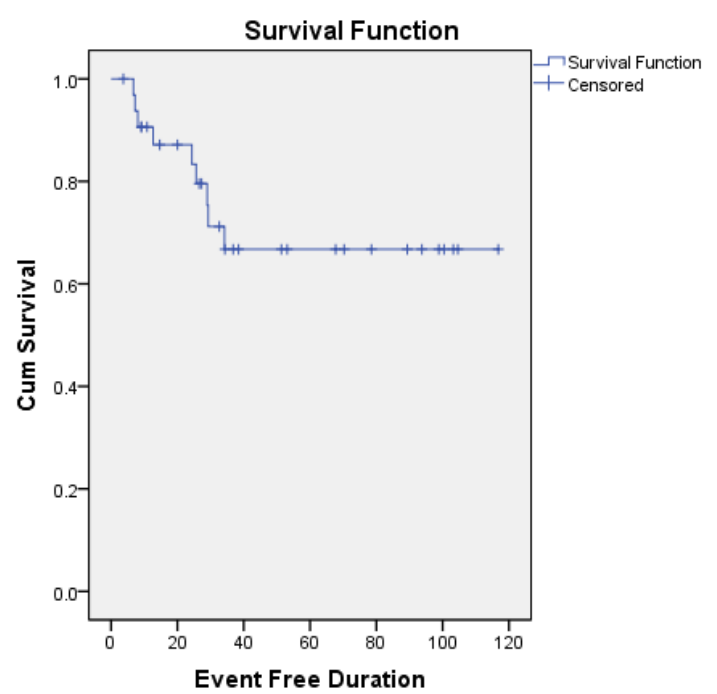

Figure 6. The 3 \& 5 Years Event-Free Survival $=68.2 \%$.

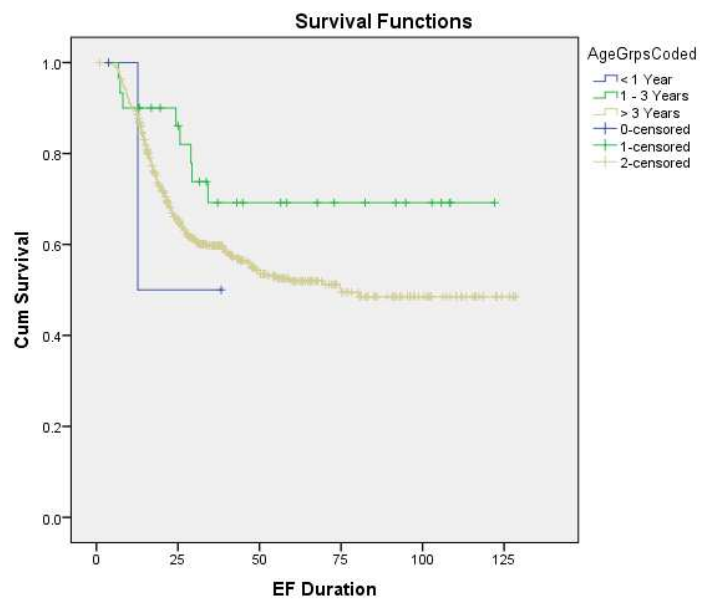

Figure $7.3 \& 5$ Years Event-Free Survival according to age was not significant $<1$ Year $(n=3) \rightarrow 1$ event $50 \%, 1-3$ years $(n=30) \rightarrow 8$ events $69.2 \%>3$ years $(n=446) \rightarrow 190$ events $59.7 \%$ (3years) $1.9 \%$ (5years), $P$ value $=0.206$.
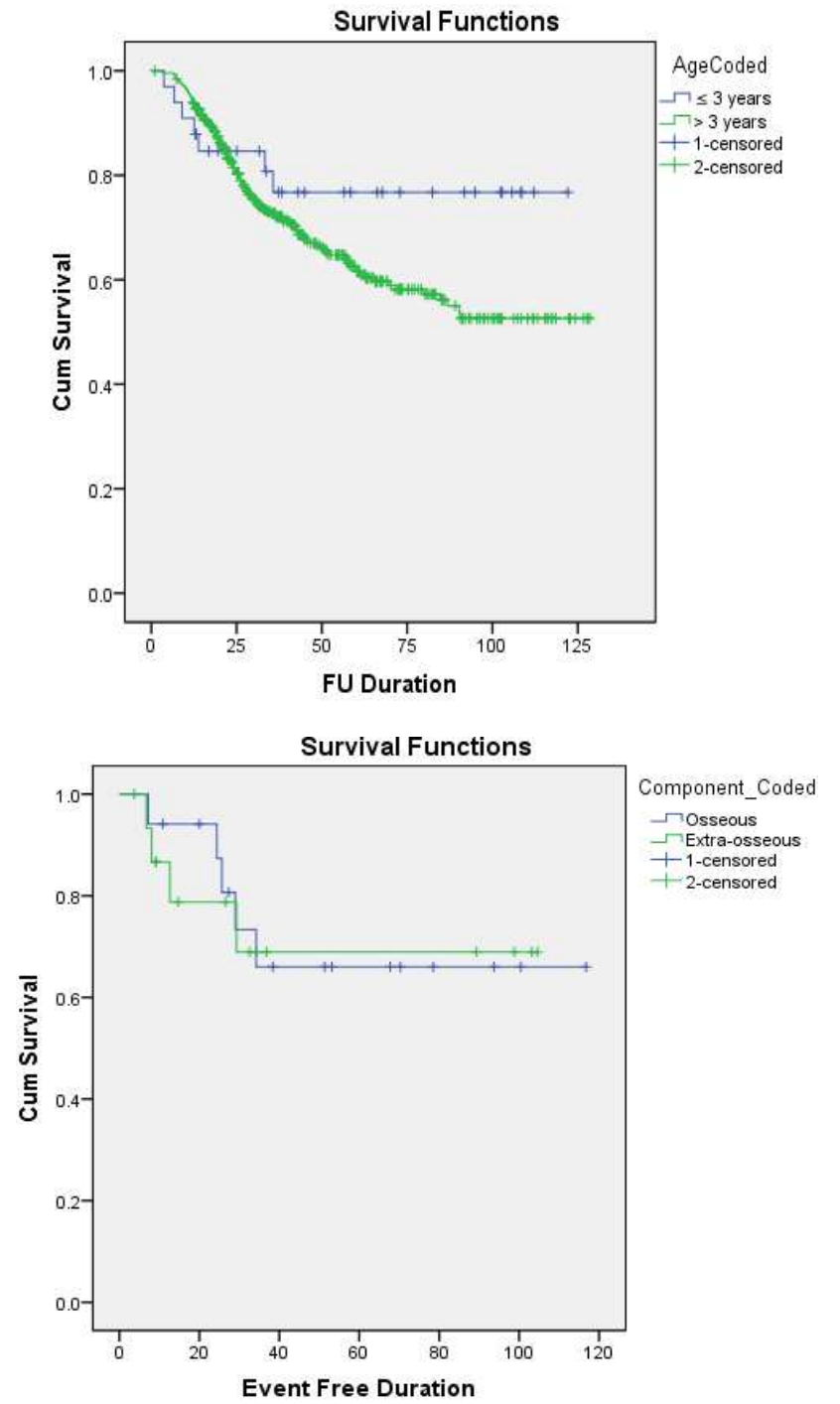

Figure 8. Osseous $(n=17) \rightarrow 5$ events $66 \%$, Extra-osseous $(n=16) \rightarrow 4$ events $68.9 \%$, $(P$-value $=0.9)$.

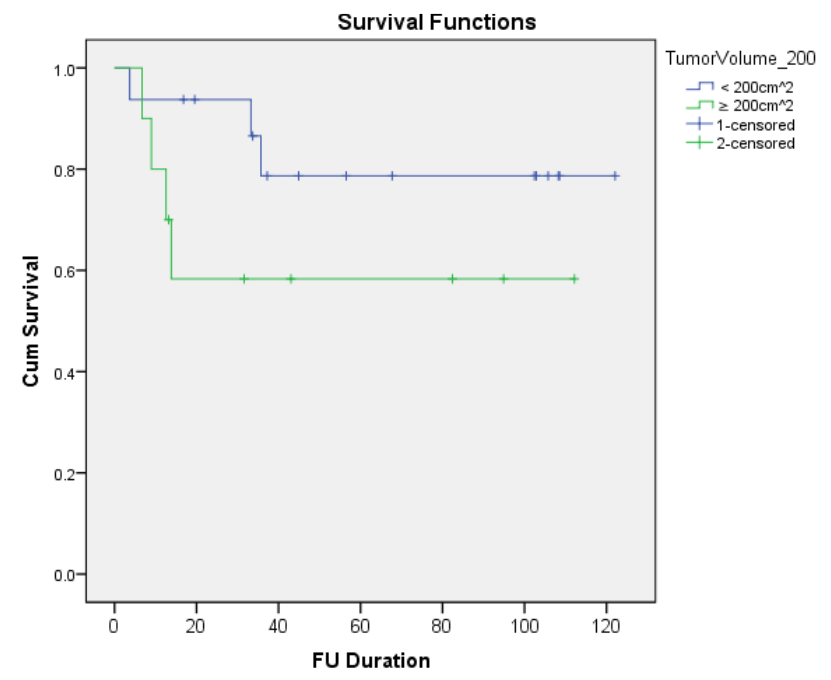

Figure 9. $<200(n=16) \rightarrow 3$ events $78.7 \%, \geq 200(n=10) \rightarrow 4$ events $58.3 \%$, When correlated to survival it was insignificant ( $P$-value $=0.166)$. 


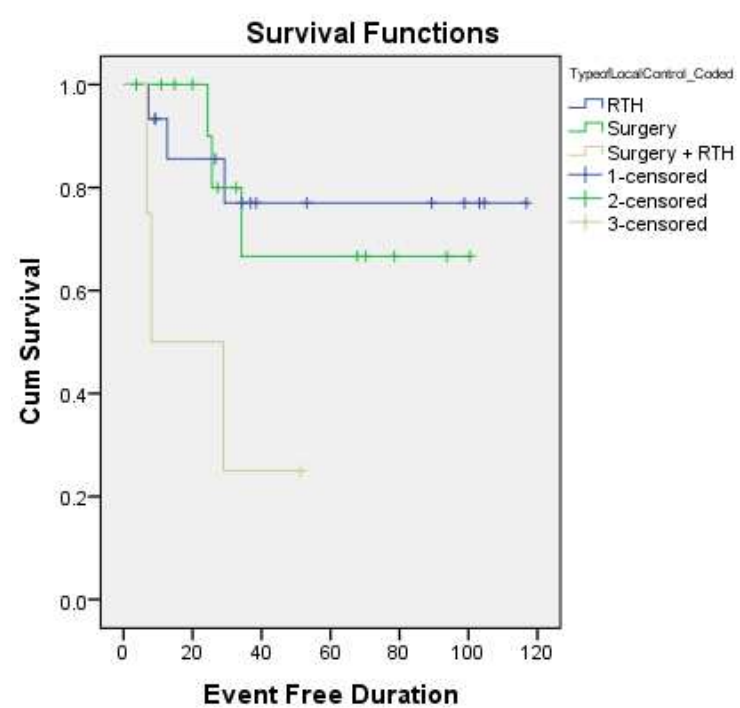

Figure 10. Patients received RTH $(n=15) \rightarrow 3$ events $77 \%$, Patients had Surgery $(n=14), \rightarrow 3$ events $66.7 \%$, Patients received both Surgery $+R T H$ $(n=4) \rightarrow 3$ events $25 \%$, $(P$-value $=0.035)$.

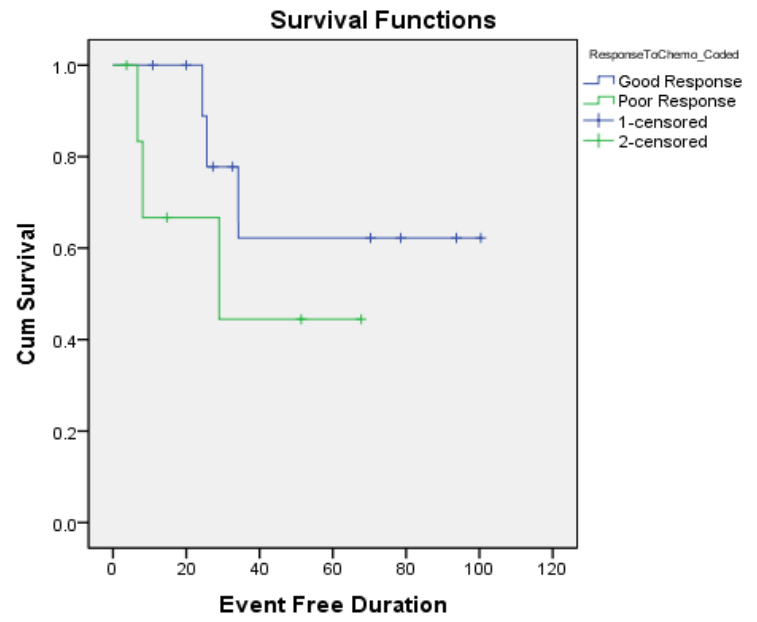

Figure 11. Pathological examination was done postoperatively in 18 patients, Good Responders ( $n=11), \rightarrow 3$ events $62.2 \%$, Poor Responders $(n=7), \rightarrow 3$ events $44.4 \%$, P-value $=(0.287)$.

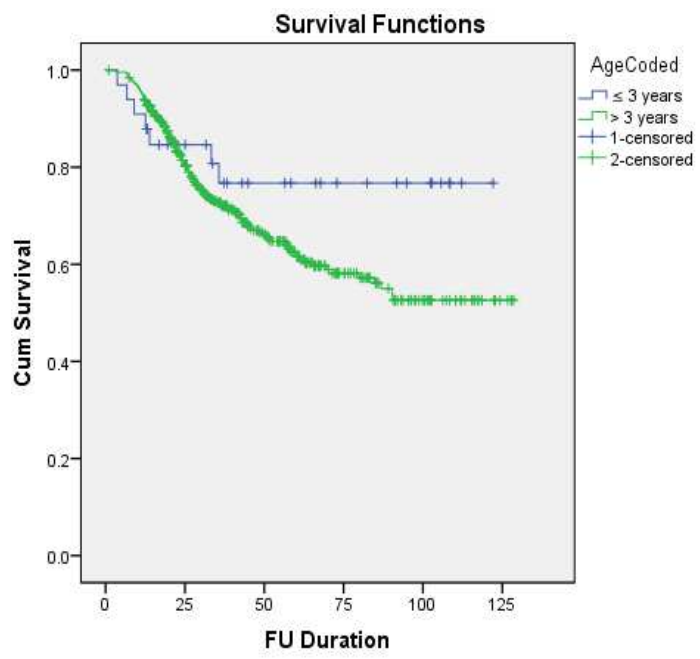

Figure 12. $\geq 3$ years $(n=33) 3$ Years Overall Survival $=76.7 \%, 5$ Years Overall Survival $=76.7 \%$ Dead $(n=7)>3$ years $(n=446) 3$ Years Overall Survival $=72.7 \%, 5$ Years Overall Survival $=61.5 \%$ Dead $(n=143)$.

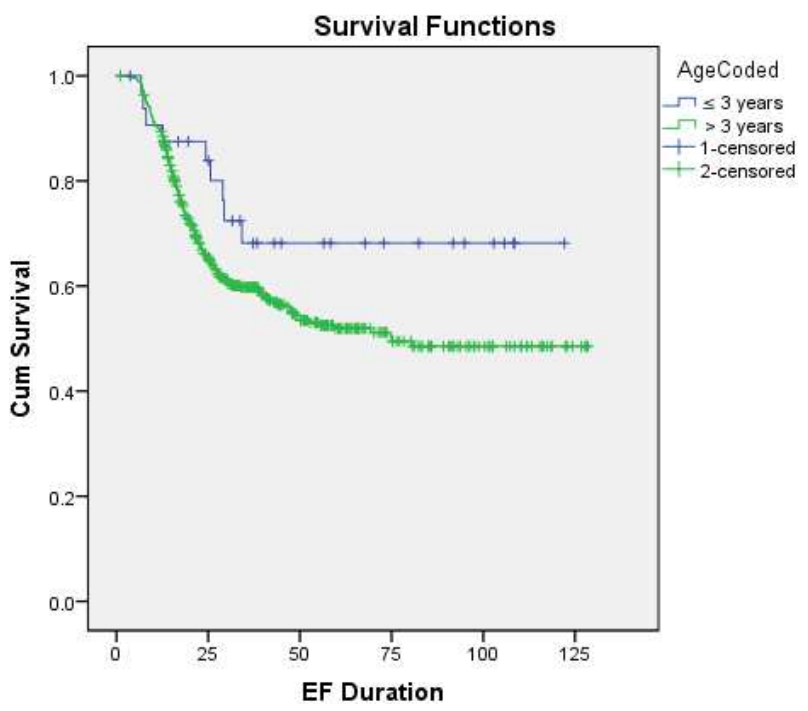

Figure 13. 3 years $(n=33) 3 \& 5$ Years Event- Free Survival $=68.2 \%(9$ event $)>3$ years $(n=446) 3$ Years EF Survival $=59.7 \%, 5$ Years EF Survival $=51.9 \%$.

\section{Statistical Methods}

A Retrospective review of the medical records was conducted to identify all the patients aged 18 or less, with pathologically-confirmed Ewing's Sarcoma/PNET, treated at the Children Cancer Hospital-Egypt, with registration date between July 2007 and December 2018.

The Overall survival was defined as the time interval from the date of registration to the date of death from any cause or last follow-up.

The Event-free survival was defined as the time interval from the date of registration to the date of the first event (disease progression or recurrence, diagnosis of a secondary malignancy, or death).

Differences in the Overall \& the Event-free survival between age groups were estimated according to the Kaplan-Meier method with $95 \%$ confidence interval (CI), and the p-values were reported from the two-sided log rank test. The statistical significance threshold was determined at a $p$-value $<0.05$.

All statistical calculations were performed using SPSS program, version 20 .

\section{Discussion}

Ewing sarcoma peaks in incidence in adolescence. Infants $<12$ months old have rarely been reported [4]. It was found ES can occur at all ages, the peak age of onset ranges from puberty to early adulthood but reports of this disease in infants are also rare [10].

In a study The median age at diagnosis was 13.7 years (range, 1.1-25.2 years) [13]. We aimed to study clinical features, treatment, and survival of infants $<3$ years and to compare those with older pediatric patients with Ewing sarcoma.

Malignancies in infancy are extremely rare. Ewing tumors are hardly ever noted in these children. Since it is generally assumed that malignancies in infancy have an extremely poor 
outcome, we wanted to investigate whether this was also the case in Ewing tumors [14].

Total number of patients enrolled from 2009 till December 2018 and below 3 years of age was 46 Patients who constituted $8.3 \%$ of all Ewing's Sarcoma patients in CCHE with $1.5 \%$ of the patients were below 12 months. This is lower than literature a, it found that infants below one year represent $2.6 \%$ of all patients registered in the Intergroup Ewing's Sarcoma Study (IESS) [8].

Significant differences in clinical characteristics between infants and older patients were observed for primary tumor site, tissue origin, and histological diagnosis. Primary tumor site was mainly axial 28 cases $(39.1 \%)$ in infants in contrast to tumors in children above 3 years which mainly had ES in the pelvis and lower extremity.

Ewing's sarcoma of the bone commonly occurs in the long bones of the limbs and the pelvis but rarely in the head and neck region [10]. In another study infants had a different distribution of primary tumor sites, with lower extremity tumors under represented. An axial primary localization was present in $66 \%$ of patients with the primary site in the chest wall in $34 \%$ Compared to older patients, infants were more likely to have soft tissue tumors [4]. This is contrary to what we found an equal distribution of soft tissue and bony lesion. This may be explained by the rarity of disease in this age group thus increasing the sample size is needed.

In our study tumor volume of the lesion was calculated and was correlated to survival, twelve patients had tumor volume $<100 \mathrm{~cm}^{3}(\mathrm{n}=12) \rightarrow 3$ events with OS $73.3 \%$ and $\geq 100 \mathrm{~cm}^{3}$ $(\mathrm{n}=14) \rightarrow 4$ events with OS $70.7 \%$.

We studied also lesions $<200 \mathrm{~cm}^{3}(\mathrm{n}=16) \rightarrow 3$ events $78.7 \%$ $\geq 200(\mathrm{n}=10) \rightarrow 4$ events $58.3 \%$.

When correlated to survival both were insignificant (Pvalue $=0.166$ and 0.675 ) may be due to small number of patients this is contrary to literature. In another study, tumor volume of $100 \mathrm{ml}$ did not distinguish groups of patients with different prognosis. However, the prognosis of patients with tumors $>200 \mathrm{ml}$ (8-year EFS rate: $42 \%$ ) was significantly inferior compared to patients with tumors both of 100 to 200 $\mathrm{ml}(70 \%)$ and of $<100 \mathrm{ml}(63 \%)$ [19].

We studied Response to chemotherapy in 18 cases after neoadjuvant chemotherapy and survival of the two groups was calculated. Good Responders $(n=11)$ had DFS 62.2\% and Poor Responders ( $\mathrm{n}=7$ ) DFS was $44.4 \%$ but correlation was insignificant with $(\mathrm{P}$-value $=0.287$. This was the same as Ahrens, 1999 where they found the histological response to chemotherapy was no longer a significant prognostic factor (EFS: $64 \%$ for good and 50\% for poor responders, respectively). This is in contrast to CESS 81 which found disease free survival for patients with a tumor volume less than $100 \mathrm{ml}$ was $75 \%$ after 41 months compared to $10 \%$ for patients with a tumor volume greater than or equal to 100 $\mathrm{m}^{3}$.

Most current therapies call for multidrug chemotherapy, consisting of cycles of varied combinations of Vincristine, Doxorubicin, Cyclophosphamide, Etoposide, Ifosfamide,
Actinomycin D, and Topotecan, followed by local therapies radiation and/or surgery [9].

Patients with localized tumors to the primary site without systemic metastasis in a pilot study of COG reported favorable outcomes [10].

In this study, The 3 Years Overall Survival of 33 patients was $75.5 \%$ and 5 Years Overall Survival was $75.5 \%$. The $3 \&$ 5 Years Event-Free Survival was $68.2 \%$.

In patients with metastatic ESFT, the 5-year EFS was $22 \%$, even after VDC-IE therapy with alternating cycles. Thus, such patients still have poor prognoses [10]. In the current study EFS was $30 \%$ in patients initially presented with metastasis relation was significant when correlated to EFS.

Surgical resection may be particularly preferable in younger patients, as radiotherapy to the developing skeleton can result in skeletal deformities and attenuated bone growth [4].

In the current study 18 cases had surgery as local control measure, 16 patients had radiotherapy and 9 patients had both. Method of local control was not significant in relation to EFS but patients who had radiotherapy as local control showed improved survival than those had surgery as local control $77 \%$ versus $66.7 \%$. This may be due to including the 8 cases who had initial surgery to patients received radiotherapy as local control. This contrary to Salah, et al 2020 who stated Inferior OS was predicted in patients with definitive radiation as opposed to definitive surgery (5-year OS $25 \%$ vs. $79 \%$, respectively, $\mathrm{p}=0.041)$ and tumor necrosis $<90 \%$ as opposed to $\geq 90 \%$ (5-year OS $55 \%$ vs. $90 \%$, respectively, $\mathrm{p}=0.01$ ).

Infants and younger patients have a better prognosis than do patients aged 15 years and older, as noted in the following studies $[15,16]$.

Review of the SEER database from 1973 to 2011 identified 1,957 patients with Ewing sarcoma. Thirty-nine of these patients (2\%) were younger than 12 months at diagnosis. Infants were less likely to receive radiation therapy and more likely to have soft tissue primary sites. Early death was more common in infants, but the overall survival (OS) did not differ significantly from that of older patients [17].

In the current study the 3 years overall Survival of the age group below 3 years was compared to patients above 3 years it was slightly better $76.7 \%$ in comparison to $72.7 \%$ but difference was insignificant (P-value $=0.151$ ). comparing the EFS of age group below 3 years to older age group $(68.2 \%$ in comparison to $59.7 \%$ difference was still insignificant $\mathrm{P}$-value $=0.112$ ). so survival of that age group was better may be due to encouraging the local control 16 patient received radiotherapy but still number of patient in comparison to that age group (46 $(9 \%)$ in comparison to whole patients 508).

\section{Conclusion}

ES in age below 3 years is a unique age group with a different management and outcome. Increasing the study 
number of patients and duration of the study should be done to assess late effects in this young age group.

\section{Children Cancer Hospital of Egypt, Sayeda Zeinab, Cairo}

$\begin{array}{ll}\text { ES } & \text { EWING SARCOMA } \\ \text { PNET } & \text { PRMITIVE NEUROECTODREMAL TUMOR } \\ \text { CCHE } & \text { CHILDREN CANCER HOSPITAL OF EGYPT } \\ \text { OS } & \text { OVERALLL SURVIVAL } \\ \text { EFS } & \text { EVENT FREEE SURVIVAL } \\ \text { VTC } & \text { vincristine, Topotecan, and Cyclophosphamide }\end{array}$

\section{Conflict of Interest}

The author declares that he has no conflict of interest.

\section{References}

[1] Rodriguez-Galindo, C, Liu, T, Krasin, MJ, Wu, J, Billups, CA, Daw, NC, Spunt, SL, Rao, BN, Santana, VM, Navid, F. Analysis of prognostic factors in Ewing sarcoma family of tumors: Review of St. Jude Children's Research Hospital studies. Cancer 2007; 110: 375-384. Wiley Online Library PubMed Science Google.

[2] Pizzo, PA, Poplack, DG. Principles and practice of pediatric oncology, 6th edition. Philadelphia: Wolters Kluwer/Lippincott Williams \& Wilkins Health; 2011. Google Scholar.

[3] Glass, AG, Fraumeni, JF. Epidemiology of bone cancer in children. J Natl Cancer Inst 1970; 44: 187-199. CAS PubMed Science Google.

[4] Thalia Wong BS Robert E. Goldsby MD Rosanna Wustrack MD Thomas Cash MD Michael S. Isakoff MD Steven G. DuBois MD, Clinical features and outcomes of infants with Ewing sarcoma under 12 months of age, Pediatric blood and cancer, volume 62, issue 11, 2015 First published: 14 July 2015 https://doi.org/10.1002/pbc.25635 Cited by: 7Funding: None.

[5] Jin SG1, Jiang XP2, Zhong L2. A Congenital Ewing's arcoma/Peripheral Primitive Neuroectodermal Tumor: A Case Report and Review of the Literature. Pediatr Neonatol. 2016 Oct; 57 (5): 436-439. doi: 10.1016/j.pedneo.2013.11.002. Epub 2014 Jan 27.

[6] Maria Antonietta De Ioris,, Arcangelo Prete, 2 Raffaele Cozza, Marta Podda, Carla Manzitti, Andrea Pession, Elisabetta Schiavello, Benedetta Contoli, Rita Balter, Franca Fagioli, Gianni Bisogno, Loredana Amoroso, Franco Locatelli, and Roberto Luksch, Ewing Sarcoma of the Bone in Children under 6 Years of Age, PLoS One. 2013; 8 (1): e53223. Published online 2013 Jan 31. Doi: 10.1371/journal.pone.0053223, PMCID: PMC3561359.

[7] Ozaki T, Diagnosis and treatment of Ewing sarcoma of the bone: a review article, J Orthop Sci. 2015; 20 (2): 250-263, PMCID: PMC436654.

[8] Susan J. Maygarden M. D. Frederic B. Askin M. D. Gene P. Siegal M. D., Ph. D. L. A. Gilula M. D. Janice Schoppe B. A.
Mary Foulkes Ph. D. John M. Kissane M. D. Mark Nesbit M. D. Ewing sarcoma of bone in infants and toddlers. A clnicopathologic report from the intergroup Ewing's study, Cancer journal, Volume71, Issue6, 15 March 1993 (A Clinicopathologic Report from the Intergroup Ewing's Study).

[9] Keir A. Ross Niall A. Smyth Christopher D. Murawski and John G. Kennedy, The Biology of Ewing Sarcoma, International Scholarly Research Notices Volume 2013 |Article ID 759725 | 7 pages | https://doi.org/10.1155/2013/759725.

[10] Eitaro Ishisaka1 \& Kenichi Usami1 \& Chikako Kiyotani2 \& Keita Terashima2 \& Hideki Ogiwara, Infantile intraorbital Ewing's sarcoma: case report and review Of the literature, 2 April 2020 \# Springer-Verlag GmbH Germany, part of Springer Nature 2020.

[11] Mascarenhas L, Felgenhauer JL, Bond MC, Villaluna D, Femino JD, Laack NN, Ranganathan S, Meyer J, Womer RB, Gorlick R, Krailo MD, Marina N (2016) Pilot study of adding vincristine, topotecan, and cyclophos- phamide to intervalcompressed chemotherapy in newly diagnosed patients with localized Ewing sarcoma: a report from the Children's Oncology Group. Pediatric Blood Cancer 63 (3): 493-498.

[12] Upasana S Ahuja, Nidhi Puri, Deepak Gupta, Shivangi Singh, Gyanendra Kumar, Ewing's Sarcoma of Mandible: A Case Report with Review, International Journal of Clinical Pediatric Dentistry 2019, 12 (5): 470-474.

[13] Samer Salah, Hadeel Halalsheh, Fawzi Abuhijla, et al, The Impact of Local Control Timing in Ewing Sarcoma, January 2020, Reports of Practical Oncology and Radiotherapy 25 (2) DOI: $10.1016 /$ j.rpor.2020.02.001.

[14] Henk van den Berg 1, Uta Dirksen, Andreas Ranft, Heribert Jürgens, Ewing Tumors in Infants, Pediatric Blood Cancer. 2008 Apr; 50 (4): 761-4. Doi: 10.1002/pbc.21292.

[15] Karski EE, McIlvaine E, Segal MR, et al.: Identification of Discrete Prognostic Groups in Ewing Sarcoma. Pediatric Blood Cancer 63 (1): 47-53, 2016. [PUBMED Abstract].

[16] Ahmed SK, Randall RL, DuBois SG, et al.: Identification of Patients With Localized Ewing Sarcoma at Higher Risk for Local Failure: A Report From the Children's Oncology Group. Int J Radiat Oncol Biol Phys 99 (5): 1286-1294, 2017. [PUBMED Abstract].

[17] Wong T, Goldsby RE, Wustrack R, et al.: Clinical features and outcomes of infants with Ewing sarcoma under 12 months of age. Pediatr Blood Cancer 62 (11): 1947-51, 2015. [PUBMED Abstract].

[18] Vohar VG. Ewing's tumor, a report on 27 cases. Indian J Radiol Imaging. 2008; 18 (2): 106-112. [Google Scholar].

[19] S Ahrens 1, C Hoffmann, S Jabar, G Braun-Munzinger, M Paulussen, J Dunst, C Rübe, W Winkelmann, A Heinecke, U Göbel, K Winkler, D Harms, J Treuner, H JürgensEvaluation of Prognostic Factors in a Tumor Volume-Adapted Treatment Strategy for Localized Ewing Sarcoma of Bone: The CESS 86 Experience. Cooperative Ewing Sarcoma Study, Med Pediatr Oncol,. 1999 Mar; 32 (3): 186-95. Doi: 10.1002/(sici)1096$911 \times(199903) 32: 3<186$ :aid-mpo5>3.0.co; 2 -d.

[20] Masood Umer, corresponding author Irfan Qadir, Nadeem Abbasi, Jai K Das, and Zohra S Lassi. Radiotherapy for localised Ewing's sarcoma in children, 2016 Oct; 2016 (10): CD011105. 
A Report from Children Cancer Hospital of Egypt

[21] Published online 2016 Oct 12. doi: [22] PMCID: PMC6457913.

10.1002/14651858.CD011105.pub2. 